\title{
Phenotypic Alterations Associated with the Bacteriophage Carrier State of Shigella dysenteriae
}

\author{
By KOIBONG LI, L. BARKSDALE AND L. GARMISE \\ New York University School of Medicine, 550 First Avenue, \\ New York, 16, N.Y., U.S.A.
}

(Received 19 August 1960)

\section{SUMMARY}

Shigella dysenteriae strain 136-R4 is lactose-negative, mannitol-negative (Lac ${ }^{-}$ $\mathrm{Mann}^{-}$) and is sensitive to bacteriophage T7. Carrier clones of strain R4 (contaminated with $\mathbf{T} \boldsymbol{7}$ ) were found to maintain their association with phage $\mathbf{T} \boldsymbol{\gamma}$ through as many as fifty consecutive single-colony isolations (from an ancestral colony which had survived lysis by phage $\mathbf{T} 7$ ). All carrier cultures (so-called pseudolysogenic strains) were found to be lactose-positive and mannitol-positive (Lac ${ }^{+}$ $\left.\mathrm{Mann}^{+}\right)$. Passage of $\mathrm{Lac}^{+} \mathrm{Mann}^{+}$bacteria through media containing antiserum directed against phage $\mathrm{T} 7$ resulted in a change back to $\mathrm{Lac}^{-} \mathrm{Mann}^{-}$and in the complete elimination of phage $\mathrm{T} 7$.

Biochemical, genetic and immunochemical evidence indicates that the change from $\mathrm{Lac}^{-} \mathrm{Mann}^{-}$to $\mathrm{Lac}^{+} \mathrm{Mann}^{+}$is the result of a phage-controlled alteration in the phenotype of Shigella dysenteriae. This dysentery bacillus is cryptic with respect to the expression of $\mathrm{Lac}^{+} \mathrm{Mann}^{+}$and the crypticity is attributable to surface structures (which are probably not a part of the $\mathbf{Y}$ or permease system). Under appropriate conditions decryptification may be brought about by phage-associated endolysin. Similar phenomena were observed in carrier strains of certain other members of the Enterobacteriaceae.

\section{INTRODUCTION}

In a previous communication (Barksdale, 1959) it was suggested that phage $\mathbf{T} 7$ is capable of converting $\mathrm{Lac}^{-}$Shigella dysenteriae to $\mathrm{Lac}^{+} \boldsymbol{S}$. dysenteriae and that this happens whether the phage T7 stocks have been derived from $\mathrm{Lac}^{-}$or $\mathrm{Lac}^{+}$ bacteria. In other words, an inherent property of bacteriophage T7 is responsible for the change from $\mathrm{Lac}^{-}$to $\mathrm{Lac}^{+}$. This phage conversion at first attracted our attention because we assumed $S$. dysenteriae to be genotypically $\mathrm{Lac}^{-}\left(Z^{-}\right)$as had Luria \& Burrous (1957a, b) and Cohn, Lennox \& Spiegelman (1960). From the data to be presented here it is evident that some strains of $S$. dysenteriae are phenotypically Lac $^{-}$(cryptic) but genotypically $\mathrm{Lac}^{+}\left(Z^{+}\right)$. Bacteriophage T7 produces an endolysin capable of decryptifying Shiga's bacillus ( $S$. dysenteriae). This 'unmasking' is non-specific in that all strains which are $\mathrm{Mal}^{-}$(maltosenegative), Mann- (mannitol-negative) and Lac- become in the presence of phage (under suitable conditions) $\mathrm{Mal}^{+} \mathrm{Mann}^{+} \mathrm{Lac}^{+}$. (Rough strains of $S$. dysenteriae grow feebly on maltose and on maltose MacConkey plates these organisms form pale pink colonies which are easily distinguishable from the red large colonies formed by phage-carrying clones.) 
The association between phage and bacterium which makes possible these alterations in phenotype has been termed the carrier state or pseudolysogenic condition (Lwoff, 1953; Jacob \& Wollman in Adams, 1959). The fact that the pseudolysogenic condition carries with it pseudogenetic effects is of some consequence for investigations concerned with bacterial and bacteriophage genetics. Decryptification by phage offers a useful tool for quickly determining the presence of hidden properties of bacteria not detectable in the phage-free state.

\section{METHODS}

Organisms. Aside from the strains of Shigella dysenteriae described herein, subcultures of the old rough strain Sh, originally used by Lisbonne \& Carrère (1923) were kindly supplied by Dr G. Bertani (Sh Bertani) and by Dr S. Spiegelman (for E. S. Lennox) and by Dr S. E. Luria (Sh 15 and Sh 16). Strain Sh 60 was sent to us by Dr W. E. van Heyningen.

Escherichia coli strains of established genetic constitution with regard to the $\beta$-galactoside system were supplied by Dr J. Monod. We are indebted to Dr N. Zinder for his strain(s) of Salmonella typhimurium.

Media. MacConkey's agar base was compounded from (g.): Bacto-peptone, 17; Proteose-peptone, 3; NaCl, 5; Bacto-agar, 13.5; Bacto Neutral red, 0.025; water to 1 l., final $\mathrm{pH} 7 \cdot 1$. Sterilized by autoclaving at $120^{\circ}$ for $20 \mathrm{~min}$. Carbohydrate supplements were added as $20 \%(\mathrm{w} / \mathrm{v})$ solution in distilled water, sterilized by filtration, sufficient being added (aseptically) to the molten agar base to yield $1 \%$ $(\mathrm{w} / \mathrm{v})$. Plates were poured to desired thickness.

Neopeptone broth consisted of Neopeptone Difco $+50 \%(\mathrm{v} / \mathrm{v})$ fresh beef infusion. Neopeptone agar consisted of Neopeptone Agar Difco $+50 \%(\mathrm{v} / \mathrm{v})$ fresh beef infusion.

PGT medium is the casein hydrolysate medium of Mueller \& Miller (1941) as modified by Barksdale \& Pappenheimer (1954).

Bacteriophage. All phages of the $\mathbf{T}$ series were derived from stocks maintained by the late Mark H. Adams. Phage PLT 22 vir (virulent) was kindly supplied by Dr N. Zinder (Rockefeller Institute). Methods and materials for phage assay were as described by Adams (1959).

Preparation of acetone powder of Shigella dysenteriae. Organisms from an actively growing culture were twice washed in saline in the cold $\left(4^{\circ}\right)$ and subsequently washed four times with eight volumes of cold acetone. Acetone from the final wash was decanted and the organisms dried to a white powder in vacuum. Plates for endolysin assay were prepared by adding $0.5 \mathrm{ml}$. of powder (resuspended in saline to optical density 5, at $590 \mathrm{~m} \mu$ as measured in a Bausch \& Lomb Jr. spectrophotometer) to $2 \mathrm{ml}$. molten soft agar and plating as a soft agar layer according to the method described by Adams (1959).

Assay for $\beta$-galactosidase. For the assay of this enzyme the method of Pardee, Jacob \& Monod (1959) was modified as follows. Toluenized extracts were not prepared because, except for organisms grown in maltose, toluenized extracts of the shigella strains used here proved to have less activity than unextracted organisms. Instead, organisms were mixed with $10^{-3} \mathrm{M}-o$-nitrophenyl $\beta$-D-galactoside in $0 \cdot 25 \mathrm{M}$ sodium phosphate buffer and incubated for $10 \mathrm{~min}$. at $28^{\circ}$. The reaction was then halted by the addition of $4 \mathrm{ml}$. cold $\mathrm{M}_{-}-\mathrm{Na}_{2} \mathrm{CO}_{3}$ and the organisms removed by 
centrifugation in the cold. The supernatant fluid was decanted and its optical density read in the Zeiss spectrophotometer at $420 \mathrm{~m} \mu$. The unit of enzyme was that amount which yielded $1 \mathrm{~m} \mu$ mole- $o$-nitrophenol $/ \mathrm{min}$. at $28^{\circ}$.

\section{RESULTS}

Shigella dysenteriae wild type (strain Sh 136-T) was isolated by one of us (L.B.) from a case of Shiga dysentery in Tokyo in 1947. Strain 136-T forms smooth translucent colonies on Neopeptone agar; it possesses a characteristic surface antigen and exhibits a low but definite virulence for mice (Barksdale, Okabe \& Li, unpublished). It is resistant to the phages $\mathbf{T} 3, \mathbf{T} 4, \mathbf{T} 5$ and $\mathbf{T} 7$. It does not ferment lactose, mannitol or maltose. A commonly encountered mutant of strain Sh 136-T forms opaque colonies (strain Sh 136-0) on Neopeptone agar, is antigenically distinguishable from wild-type, is of a lower order of virulence for mice and can support the multiplication of phage T7. From strain Sh 136-0 a number of rough mutants have been derived. Those important to this report are Sh 136-R 1, Sh 136-R 2 and Sh 136R4. Those are all less virulent for mice than strains 136-T and 136-0. They belong to the class of rough Shigella dysenteriae and therefore have much in common with the rough strains: Sh (Bertani), Sh 15 of Luria (see Adams \& Luria, 1958) and Sh 60 of Van Heyningen (1955). It can be seen from Table 1 that rough strains were capable of adsorbing and supporting the growth of more different phages of the T series than was the wild-type 136-T. For example, strain 136-T is resistant to phage $T 7$, whereas strain $136-R 4$ is sensitive to $T 7$.

Table 1. Efficiency of plating* of coliphages on Shigella dysenteriae

\begin{tabular}{|c|c|c|c|c|c|c|c|}
\hline \multicolumn{8}{|c|}{ Bacteriophage } \\
\hline $\mathbf{T} 1$ & T2 & T3 & $\mathbf{T 4}$ & T5 & $\mathbf{T} 6$ & $\mathbf{T r}$ & $\mathrm{T} 7^{\mathrm{sh}}$ \\
\hline \multicolumn{8}{|c|}{ Efficiency of plating $(\%)^{*}$} \\
\hline 84 & 1 & $\mathbf{r}$ & $\mathbf{r}$ & $\mathbf{r}^{\prime \prime}$ & 5 & $\mathbf{r}$ & $0 \cdot 3$ \\
\hline 180 & 39 & $\mathbf{r}$ & $\mathbf{r}$ & $\mathbf{r}^{\prime \prime}$ & 0.01 & 1.8 & $1 \cdot 0$ \\
\hline 100 & 85 & 97 & $\mathbf{r}$ & 46 & 96 & 195 & 150 \\
\hline 127 & 93 & 50 & $\mathbf{r}$ & 81 & 22 & 110 & 350 \\
\hline 103 & 86 & 93 & $\mathbf{r}^{\prime \prime}$ & 71 & 81 & 432 & 520 \\
\hline $\mathbf{r}$ & 73 & 95 & 0.001 & $\mathbf{r}$ & 1 & 126 & $\mathbf{3 3}$ \\
\hline 102 & $0 \cdot 01$ & 14 & 100 & 180 & 100 & 104 & 67 \\
\hline 93 & 90 & 0.5 & 26 & 67 & 54 & 98 & 130 \\
\hline
\end{tabular}

* EOP $=\frac{\text { Number of plaques formed on Shigella }}{\text { Number of plaques formed on E. coli } \mathrm{B}} \times 100$.

$\mathbf{r}=$ resistant, as indicated by failure of plaque formation in any dilution of stocks containing $10^{10}$ particles $/ \mathrm{ml}$.

$r^{\prime \prime}=$ resistant but lysed by phage endolysin (this category includes lysis from without).

Though sensitive to phage $\mathbf{T} 7$, clones of $136-\mathrm{R} 4$ were found to enter a carrier relationship with this bacteriophage, so that the virus persisted with the bacteria through many generations. Our carrier strains were first isolated as supposed bar mutants of 136-R4 resistant to phage T7 (136-R 4/7). Drops (approximately $0.025 \mathrm{ml}$. $)$ of phage $\mathrm{T} 7\left(5 \times 10^{10}\right.$ particles $/ \mathrm{ml}$. $)$ were placed on lawns of 136-R 4 . 
After several days of incubation at $30^{\circ}$ there appeared in the middle of the lysed area, colonies of resistant bacteria (see Demerec \& Fano, 1945). Some of these were picked and streaked on agar plates to obtain isolated clones free from contaminating phage. A number of the colonies derived from this first plating exhibited a nibbled appearance. Restreaking of entire (non-nibbled) colonies yielded some nibbled and some entire colonies. After fifty successive restreakings of entire colonies, nibbled colonies and entire colonies continued to segregate. Since T7 is a virulent phage, it seemed unlikely that it had been perpetuated as prophage in the cultures. Cultivation of phage-carrying clones in anti-T7 serum resulted in a complete elimination of the virus. The phage-free bacteria so treated were again sensitive to $\mathrm{T} 7$.

\section{Presence of phage associated with Lac ${ }^{+}$condition}

When the streaking which led to the segregation of entire and nibbled colonies was carried out on lactose agar plates containing neutral red as an indicator (MacConkey's agar), red colonies (lactose-positive) and colourless colonies (lactose-negative) developed on the plates. Some of the red colonies were obviously nibbled and some were entire. When 10 red colonies were suspended in $1 \mathrm{ml}$. broth, centrifuged and the supernatant fluid assayed for phage, phage was present in each of the 10; none of 10 colourless ( $\left.\mathrm{Lac}^{-}\right)$colonies, so examined, contained phage. When the bacteria from a $\mathrm{Lac}^{+}$colony were suspended in anti-Tr serum and subsequently plated on lactose plates, only $\mathrm{Lac}^{+}$colonies grew out. Thus it appeared that $\mathrm{Lac}^{+}$ colonies always carried virus and, on subculture, always segregated $\mathrm{Lac}^{+}$and $\mathrm{Lac}^{-}$ colonies. Furthermore it became apparent that $\mathrm{Lac}^{+}$was a more reliable index to the presence of virus in a colony than was the state of the margin of the colony (nibbled versus entire). The first question these observations raised was 'where is the lactose-positiveness coming from?' The phage $\mathbf{T} 7$ preparations were originally grown on Escherichia coli B, a lactose-positive organism. So, starting from a single plaque of T7 on 136-R4 (a supposed lactose-negative organism) a stock of T7 was prepared by growth on this shigella. The preparation of phage so obtained was designated $T 7^{\mathrm{gh}}$. It differed from $\mathrm{T} 7$ slightly (see Table 2 ) but was able satisfactorily to establish the carrier condition with 136-R4. The carrier clones were $\mathrm{Lac}^{+}$.

Table 2. Host ranges of phages $T \boldsymbol{7}$ and $T 7^{\mathrm{sh}}$

\begin{tabular}{lcc} 
Bacterium & \multicolumn{2}{c}{ Lysis by } \\
\cline { 2 - 3 } Shigella 136-T & - & T $^{\mathrm{sh}}$ \\
Shigella 136-R4 & + & + \\
Coli W-2241 & + & +
\end{tabular}

One interesting fact about the phages $T$ 7 and $T \gamma^{\text {sh }}$ multiplying on Shigella 136-R4 is worthy of note. The one-step growth curves obtained from the growth of $\mathrm{T} 7$ and $\mathbf{T} 7^{\text {sh }}$ on strain Escherichia coli B were quite different from those obtained on shigella 136-R 4. In the case of strain 136-R 4 there appeared to be two separate bursts: one occurred from the 19th to the 30th minute; the other, from the 35th to the 52nd minute. The greatest increment of phage came from the late-lysing 
population. This effect was observed only under standard conditions of phage growth (Adams, 1959) where nutrient broth or Neopeptone broth were employed. Experiments carried out in the semi-defined PGT medium (casein hydrolysate) yielded data similar to that shown in Fig. $1 a$.
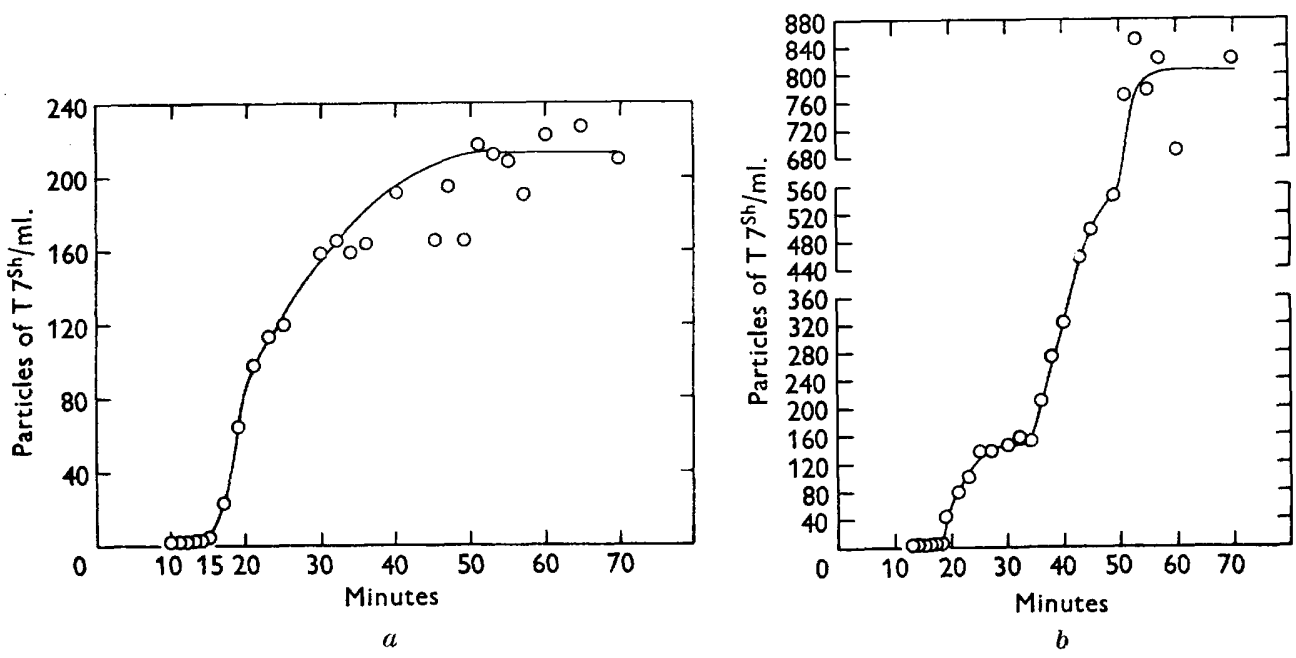

Fig. 1a. One-step growth curve of $\mathrm{T} 7^{\text {sh }}$ grown on Escherichia coli B. Multiplicity of phage to bacterium $=0 \cdot 1$. Multiplicity was calculated from titre as determined on E. coli B (concentration of bacteria: $1.5 \times 10^{8}$ bacteria $/ \mathrm{ml}$.).

Fig. $1 b$. One-step growth curve of $T 7^{\text {sh }}$ on Shigella dysenteriae 136-R4. Multiplicity of phage to bacterium $=0 \cdot 1$. Multiplicity was calculated from titre as determined on Sh. 136-R4 (concentration of bacteria $1.5 \times 10^{8}$ bacteria $/ \mathrm{ml}$.).

\section{The carrier colony}

Carrier colonies which grew out on MacConkey's agar developed as completely red (lactose-positive) colonies or as sectored colonies (lactose-positive sectors alternating with lactose-negative sectors). As the sectored colonies aged, they became completely red. Restreakings of sectored colonies yielded $\mathrm{Lac}^{+}$and $\mathrm{Lac}^{-}$colonies. Microscopic examination of organisms from $\mathrm{Lac}^{-}$colonies revealed short rodshaped bacteria. Organisms from $\mathrm{Lac}^{+}$colonies were swollen spheroplast-like structures; sometimes with pieces of material adhering to their surfaces, much as portions of cell wall adhere to the membranes of freshly prepared spheroplasts (See drawings in Lederberg, 1956, which show a similar appearance). Occasionally, these swollen structures occurred in short chains of three to five units flattened at their abutting sides. Larger fragments of cell wall appeared to be retained by organisms in chains than by single units. These spheroplast-like structures (demispheroplasts) were osmotically fragile. They were not observed on Gram-stained preparations but were readily visible in wet mounts prepared in $20 \%(\mathrm{w} / \mathrm{v})$ sucrose. When the bacterial mass was taken from one colony, suspended in sucrose broth, diluted in sucrose broth and plated, the number of viable units was about $5 \times 10^{5}$. This is one hundred to one thousand times fewer viable units than one would expect from an uninfected bacterial colony of similar size. 


\section{Osmotic fragility of carrier clones}

The osmotic fragility of a carrier colony was tested by suspending the colony in sucrose, diluting half of the suspension in sucrose broth and half in plain broth and comparing the viable units obtained by plating on MacConkey's agar. Eighty \% more survivors occurred on the platings from sucrose than on those from broth. Seventy-five $\%$ of the sucrose survivors were $\mathrm{Lac}^{+}$whereas only $12 \%$ of the broth survivors were $\mathrm{Lac}^{+}$, thus suggesting that the organisms likely to give rise to $\mathrm{Lac}^{+}$ clones were osmotically more fragile than those likely to give rise to $\mathrm{Lac}^{-}$clones. A probable explanation for the extreme fragility of these organisms was found. Phages $\mathrm{T} 7^{\text {sh }}$ and $\mathrm{T} 7$, like so many bacteriophages, produce plaques with a central clear area surrounded by a halo (opaque zone) in which the appearance of the bacterial mass is different from that existing beyond the plaque and comprising the unaffected lawn. While the bacteria in the halo have an obvious alteration in their optical properties, they are not infected with phage; no phage can be obtained from them. The endolysin responsible for their appearance is also capable of bringing about the lysis of dead bacteria. In Pl. 1, figs. 1, 2, is shown a hole formed in a lawn of dead dysentery bacilli (acetone-powder) by phage $\mathbf{T} 7$ endolysin.

It is very well established that endolysins are capable of removing specific phage receptors (Adams \& Park, 1956; Adams, 1959). Bacteria which have lost their receptors, either by enzymic action or as a result of mutation, are immune to attachment by the whole phage (Spizizen, 1957). Thus the bacteria in a halo are immune to phage much as are spheroplasts. The bacteria in a Shigella dysenteriae carrier strain presumably owe their immunity to endolysin generated by the small number of bacteria in which phage succeeds in multiplying.

How does the first bacterium of a carrier clone survive infection? In Table 3 is shown the incidence of $\mathrm{Lac}^{+}$survivors at various multiplicities of phage to bacteria. Each of these $\mathrm{Lac}^{+}$clones must have been initiated by a bacterium which had escaped lysis. Fraser (1957) in experiments carried out in microdrops established that certain mutants of phage $\mathrm{T} 3$ gave rise to lasting complexes with Escherichia coli B. 'The complexes' (bacteria infected with phage) 'can increase in length, divide and give phage-sensitive uninfected segregants before lysis'. We found that phage T3 gave Lac ${ }^{+}$carrier clones with both Shigella dysenteriae and $S$. sonnei. Whilst we have carried out no single-cell studies, we feel that Fraser's findings offer a reasonable explanation for the origin of our carrier clones: the initially infected ancestral bacterium fails to lyse, reaches a spot on an agar plate, divides to give rise to an infected and uninfected daughter. This process may be repeated several times before lysis actually occurs. (Of course a few bacteria in the population might very well have their receptors destroyed and escape infection and arrive on the plating medium in a receptorless state, etc.). With lysis there is liberation of phage and endolysin. Bacteria geographically so located that they absorb phage may subsequently lyse. Bacteria bathed in endolysin become immune as they lose their receptors. Eventually, an equilibrium is reached between phage, susceptible bacteria and immune bacteria. Susceptible bacteria are necessary for continued generation of endolysin. This equilibrium may be destroyed by antiphage serum or by dilution into broth or other media having little or no osmotic buffering capacity. 
Table 3. Incidence of carrier clones (136-R $\left.4 . T 7^{\mathrm{Bh}}\right)$ when $1 \times 10^{8}$ organisms of Shigella dysenteriae 136-R 4 were infected with various multiplicities of phage $T 7^{\mathrm{sh}}$

$\begin{array}{cccc}\begin{array}{c}\text { Ratio of } \\ \text { phage to } \\ \text { bacteria }\end{array} & \begin{array}{c}\text { Dilution } \\ \text { of infected } \\ \text { culture which } \\ \text { was plated }\end{array} & \begin{array}{c}\text { No. of } \\ \text { Lac } \\ \text { survivors }\end{array} & \begin{array}{c}\text { Lac } \\ \text { survivors } \\ \text { as \% of } \\ \text { total } \\ \text { survivors }\end{array} \\ 50 & 10^{-1} & 0 & - \\ & 10^{-2} & 2 & 33 \\ & 10^{-3} & 27 & 28 \\ 10 & 10^{-4} & 2 & 67 \\ & 10^{-1} & 0 & - \\ & 10^{-2} & 8 & 12 \\ 1 \cdot 0 & 10^{-3} & 20 & 33 \\ & 10^{-4} & 2 & 40 \\ & 10^{-1} & 0 & - \\ 0.1 & 10^{-2} & 30 & 23 \\ & 10^{-3} & 3 & 60 \\ & 10^{-4} & 0 & - \\ & 10^{-1} & 0 & - \\ & 10^{-2} & 10 & 5 \\ & 10^{-3} & 1 & 2 \\ & 10^{-4} & 0 & -\end{array}$

Evidence for the presence of $\beta$-galactosidase in Shigella dysenteriae

The effect of methyl-thio- $\beta$-D-galactoside $(T M G)$ on the degree of $\beta$-galactosidase activity in culture of 136-R4. Following a discussion with Dr H. Rickenberg about the possible presence of $\beta$-galactosidase in Shigella dysenteriae, we found that 136-R 4 organisms grown in PGT medium produced appreciable amounts of enzyme when methylthio- $\beta$-D-galactoside (TMG) was present. In Table 4 are shown the results of growing strain 136-R 4 in PGT medium with no added carbohydrate, with $2 \%$ maltose and with $10^{-3} \mathrm{M}-\mathrm{TMG}$.

Table 4. $\beta$-Galactosidase synthesis by Shigella dysenteriae 136-R4 Grown in PGT medium

$\begin{array}{lccc} & \begin{array}{c}+ \\ \text { Maltose }\end{array} & + & \\ & 3 \cdot 1 & 2 \cdot 6 & \text { No addition } \\ \text { Optical density* } & 0 \cdot 11 & 11 \cdot 6 & 2 \cdot 75 \\ \text { Units of enzyme } & 0 \cdot 035 & 4 \cdot 4 & 0 \cdot 026 \\ \text { Units enzyme } & 10^{\circ} \text { bacilli }\end{array}$

* O.D. $1 \cdot 0=1 \times 10^{9} 136-\mathrm{R} 4$ organisms $/ \mathrm{ml}$.

Similar results were obtained with Shigella strain Sh 60 . Strain Sh 15, however, showed about $\frac{1}{800}$ th the activity of shigella 136-R4.

The occurrence of $\mathrm{Lac}^{+}$mutants of $136-\mathrm{R} 4$. When bacteria were plated so that about 5 to 10 well-isolated colonies developed on a single plate the diameter attained by each colony (with prolonged incubation) might be as much as 10-15 mm. (so-called giant colonies). Thick MacConkey's agar plates (lactose) containing giant 
colonies of strain 136-R 4 were sealed with masking tape and incubated for 8 weeks at $30^{\circ}$. During this time several red papillae appeared on the colonies of 136-R4. Four bacterial lines developed from an equal number of papillae (136-R 4-L-1, -L-2, -L-3 and -L-4) all proved to give positive fermentation reactions in standard lactose fermentation tubes. When one of these mutants was tested for enzyme activity, its basal level was found to be much greater than that of 136-R4 (see Table 5).

Table 5. $\beta$-Galactosidase production by mutant shigella $136-R$ - $4-L-1$ when grown in PGT medium with the indicated additions

\begin{tabular}{|c|c|c|c|c|c|c|c|}
\hline & $\begin{array}{c}\text { No } \\
\text { addition }\end{array}$ & $\begin{array}{c}\text { Maltose } \\
2 \%\end{array}$ & $\begin{array}{c}\text { Glycerol } \\
\mathbf{2} \%\end{array}$ & $\begin{array}{c}\text { Glucose } \\
2 \%\end{array}$ & $\begin{array}{c}\text { Lactose } \\
1 \%\end{array}$ & $\begin{array}{l}\mathrm{TMG}^{*} \\
10^{-3} \mathrm{M}\end{array}$ & $\begin{array}{l}\text { IPGT } \dagger \\
10^{-4} \mathrm{M}\end{array}$ \\
\hline Optical density & $2 \cdot 8$ & $\mathbf{3} \cdot \mathbf{3}$ & $\mathbf{2 \cdot 2}$ & $1 \cdot 4$ & $2 \cdot 8$ & $1 \cdot 8$ & $2 \cdot 8$ \\
\hline$\frac{\text { Units } \beta \text {-galactosidase } \ddagger}{10^{9} \text { bacilli }}$ & $5 \cdot 8$ & $6 \cdot 3$ & $\mathbf{3 \cdot 3}$ & $\mathbf{2} \cdot \mathbf{9}$ & $15 \cdot 1$ & $\mathbf{5} \cdot \mathbf{3}$ & $11 \cdot 2$ \\
\hline
\end{tabular}

* The presence of TMG in the medium resulted in a 'stickiness' of the bacteria, i.e. on standing they sedimented to form a tightly adhesive mass. This phenomenon was observed only in the case of organisms grown with TMG.

$\dagger$ Isopropyl-thio- $\beta$-D-galactoside was kindly provided by Dr S. E. Luria from a sample from Dr D. Türk (Institut Pasteur, Paris).

$\ddagger 1$ unit enzyme is that amount which produces $1 \mathrm{~m} \mu$ mole $o$-nitrophenol/min. at $28^{\circ}, \mathrm{pH} 7 \cdot 0$ (see Pardee et al. 1960).

The occurrence of $\mathrm{Lac}^{+}$recombinants in the cross $\mathrm{H} f \mathrm{fr}\left(\mathrm{Z}^{-}\right) \times \mathbf{1 3 6}-\mathrm{R} 4$. It was previously established (Barksdale, 1959) by radioisotope experiments carried out with Dr M. J. Osborn of this department that, under conditions where Escherichia coli ML30 showed normal uptake of labelled ${ }^{35} \mathrm{~S}$ thio- $\beta$-D-digalactoside, 136-R 4 was unable to concentrate this substrate. If $136-\mathbf{R} 4$ is truly a cryptic strain, then one should be able to eliminate its crypticity by bringing about a genetic alteration of its surface. Mating between shigella and $\boldsymbol{E}$. coli strains was first accomplished by Luria \& Burrous $(\mathbf{1 9 5 7} b)$. We have for some time been using this ability to mate as one of several means of characterizing various strains of Shigella dysenteriae and we find that rough strains undergo mating and recombination with various $\mathrm{Hfr}$ strains of $E$. coli. Dr S. E. Luria kindly supplied us with a strain of Hfr characterized as: Hfr $(\lambda) \mathbf{M}^{-} \mathbf{P r}^{-}$Lac 72 (extreme $\mathbf{Z}^{-}$type deletion). The genetic designations $\mathbf{Y}$ (permease), Z ( $\beta$-galactosidase) and $\mathrm{i}$ (inducibility) refer to that Escherichia coli chromosomal segment governing the $\beta$-galactoside system. By using a streptomycin-resistant mutant of strain 136-R4 (136-R4 $\mathrm{S}^{\mathrm{r}}$ ) as an $\mathrm{F}^{-}$(acceptor) parent, a mating was carried out: $1 \times 10^{8}$ organisms of $136-\mathrm{R} 4 \mathrm{~S}^{\mathrm{r}} \mathrm{Lac}^{-}$non-motile were combined with $3 \times 10^{9}$ organisms of $\mathrm{H} f r S^{s}$ Lac $^{-}(Z$ deletion) motile and incubated with gentle shaking for $100 \mathrm{~min}$. Dilutions of the mating mixture were then plated on MacConkey's lactose agar containing $1 \mathrm{mg}$. streptomycin $/ \mathrm{ml}$. Control platings were made of the donor strain and of the acceptor strain. After incubation for $48 \mathrm{hr}$. at $37^{\circ} \mathrm{Lac}^{+}$colonies were found on platings from the lower dilutions of the mated mixture. There were no $\mathrm{Lac}^{+}$colonies on the acceptor control plates; there was no growth on the donor control plates. Following restreaking and 'purification', the recombination clones proved to be non-motile, $S^{r}$ and frankly lactose-positive organisms. Since both parental organisms were $\mathrm{Lac}^{-}$and since it is well established that the donor strain harbours a deletion with regard to $\mathbf{Z}^{+}$, it seems evident that $\mathbf{Z}^{+}$ 
of the recombinants must have been furnished by the shigella parent. The Lac $^{+}$ condition (arising from the cross of $\mathrm{Lac}^{-} \times \mathrm{Lac}^{-}$) in all probability resulted from the influence of donor genes upon the surface properties (permeability to $\beta$-galactosides) of the recombinant. In this connexion it should be pointed out that some years ago Luria \& Burrous (1957a) found a correlation between alteration in serotype and lactose-positiveness in crosses between $E$. coli and Shigella flexneri. They were so impressed with this apparent relationship (between serological type and $\mathrm{Lac}^{+}$) that they stated: 'The new serotype is controlled by a genetic factor closely linked to, but not identical with, the Lac locus.'

The relationship of Escherichia coli $\beta$-galactosidase to the $\beta$-galactosidase of Shigella dysenteriae

We are much indebted to Drs M. Cohn, S. Spiegelman and E. Lennox for a generous supply of purified Escherichia coli $\beta$-galactosidase and of its antiserum (rabbit). Without these we should not have attempted to establish the immunochemical identity of the $\beta$-galactosidase derived from $E$. coli and that derived from Shigella dysenteriae strain 136-R4. The simplest method of making an immunochemical survey of the various enzymes, toxins and other antigens produced by microorganisms is through the use of crude lysates and purified known antigens and antibodies reacting in an agar medium. (It was while experimenting with phage $\mathrm{T} \tau$ endolysin as an agent for releasing Shiga neurotoxin that we observed the Lac ${ }^{+}$ carrier clones of Shigella dysenteriae.) In Pl. 2, fig. 4 is shown the reaction of $\beta$-galactosidase (released by a $T 7^{\text {Bh }}$. 136-R 4 carrier clone) from lysing $S$. dysenteriae with anti-serum against $E$. coli $\beta$-galactosidase. It can be seen that the lines formed by the reaction shigella $\beta$-galactosidase $v$. coli anti- $\beta$-galactosidase are continuous with the lines resulting from the reaction of purified coli $\beta$-galactosidase $v$. coli anti- $\beta$-galactosidase. The plate shown in Pl. 2 , fig. 4 was set up in the following way. Plates of MacConkey's agar base (without neutral red) containing $10^{-\mathbf{3}} \mathrm{M}$-TMG as the only added 'carbohydrate' were poured to yield thick layers of agar. Upon each plate were placed 3 disks of Whatman no. 50 filter paper (diam. $13 \mathrm{~mm}$.) as shown in Pl. 2, fig. 4. To disks 1 and 3 were added $0.03 \mathrm{ml}$. undiluted rabbit antiserum directed against a purified $\beta$-galactosidase. To disk number 2 was added $0.02 \mathrm{ml}$. containing $360 \mu \mathrm{g}$. (protein) of purified $\beta$-galactosidase. To position 4 was added $0.01 \mathrm{ml}$. of a freshly prepared lysate of strain 136-R 4 resulting from the action of bacteriophage $\mathrm{T} 7^{\mathrm{sh}}\left(5 \times 10^{9} \mathrm{~T} 7\right.$ particles $/ \mathrm{ml}$. in combination with $1 \times 10^{9}$ 136-R4 organisms/ml.). After incubation for 7 days at $30^{\circ}$ definite single lines developed between the $\beta$-galactosidase (position 2 ) and the anti- $\beta$-galactosidase (positions 1 and 3 ) and these fused with the major component which developed between the carrier clone and the anti- $\beta$-galactosidase (of positions 1 and 3). There seems little doubt, then, that the $\beta$-galactosidase of $E$. coli and $S$. dysenteriae 136-R 4 are immunochemically identical. Similar results obtained with strains Sh 60 and Sh 15. The latter strain produce very small amounts of enzyme.

Non-specific nature of the effect of bacteriophage on the phenotype of Lac-strains

The key character upon which depends the taxonomic delineation of subgroups in the genus Shigella is that of mannitol fermentation (+ or -$)$. S. dysenteriae is 
mannitol-negative. It seemed evident to us that if the effect of phage $T$ r on the phenotype 136-R 4 was merely an alteration of permeability by endolysin action, then permeability to some other sugars not used by $S$. dysenteriae should also be altered in clones of $136-\mathrm{R} 4$ carrying phage $\mathrm{T} 7^{\mathrm{sh}}$. This would be true were $S$. dysenteriae cryptic with respect to enzymes needed for the dissimilation of certain other sugars. MacConkey agar plates containing salicin, mannitol or maltose were prepared and $\mathrm{Lac}^{+}$carrier clones from lactose plates (MacConkey agar) were transferred to these. All $\mathrm{Lac}^{+}$clones proved to be maltose-positive and mannitolpositive but not salicin-positive. As indicated earlier, on maltose plates $\boldsymbol{S}$. dysenteriae formed slightly pink colonies; the carrier clones yielded bright red colonies which attained a larger size than uninfected colonies.

\section{The universality of the effect of bacteriophage on the phenotype of carrier clones}

When the Zinder strain of Salmonella typhimurium (stm) becomes infected with a virulent mutant of phage PLT 22 (Zinder, 1957) the carrier state is established. These carrier clones show no alteration in their fermentative properties on lactose plates. However, on maltose and on mannitol agar the infected populations formed deep red colonies in contrast to the pink ones formed by uninfected populations. Passage of infected populations through anti-PLT22 serum (kindly supplied by Dr Zinder) restored the native state of $S$. typhimurium.

Escherichia coli $\mathrm{K} 12 \mathrm{~W} 2241\left(\mathrm{Y}^{-} \mathrm{Z}^{+} \mathrm{i}^{+} \mathrm{Mal}^{+}\right)$when infected with phage $\mathrm{T}^{\mathrm{sh}}$ at a multiplicity of 5 yielded $2 \cdot 1 \mathrm{Lac}^{+}$survivors $/ 10^{7}$ bacteria. Among $\mathrm{Lac}^{+}$colonies developing on MacConkey medium plates some were carriers and some contained $\mathrm{Lac}^{+}$back mutants. Plating of the same material on mannitol plates, however, clearly distinguished between red carriers and colourless uninfected survivors. Neutralization of red clones with $\mathrm{T} 7$ antiserum resulted in a return to the 'colourless' state.

In the case of the formation of carrier colonies between phage $\mathbf{T} 7^{\text {sh }}$ and Escherichia coli $\mathrm{K} 12 \mathrm{~W} 2242\left(\mathrm{Y}+\mathrm{Z}-\mathrm{i}^{+} \mathrm{Mal}^{+}\right)$and $\boldsymbol{E}$. coli $\mathrm{K} 12 \mathrm{~W} 2244\left(\mathrm{Y}^{+} \mathrm{Z}-\mathrm{i}^{+} \mathrm{Mal}^{+}\right)$, no $\mathrm{Lac}^{+}$ clones were detected. Red phage-infected colonies did develop on mannitol plates and on maltose plates, however, and this condition was reversed by passage in antiT7 serum. Carrier clones of $\mathbf{H f r} \mathbf{Z}^{-}(\mathrm{W}-4032)$ were also lactose-negative. E. coli ML3 $\left(\mathrm{Y}^{-} \mathrm{Z}^{+} \mathrm{i}^{+}\right)$and ML3080 $\left(\mathrm{Y}^{-} \mathrm{Z}^{-} \mathrm{i}^{-}\right)$were both resistant to phages $\mathrm{T} 7$ and $\mathrm{T} 7^{\mathrm{sh}}$. When combined with either of these phages and plated on lactose plates, no Lac ${ }^{+}$ clones developed. The high rate at which these strains mutated to $\mathrm{Lac}^{+}$made it necessary to select a fresh $\mathrm{Lac}^{-}$colony for each experiment.

\section{DISCUSSION}

It is a common practice among geneticists to characterize mutant organisms over the common denominator of their ancestral wild type. There is always some variation among wild strains and the taxonomists in selecting type strains (ideally) attempt to choose one that is a happy medium of those extremes found in nature. Some years ago we examined several wild type strains of Shigella dysenteriae in an effort to find out what, if anything, distinguishes this organism, freshly isolated from cases of dysentery, from various laboratory strains designated as $S$. dysenteriae. Wild type $S$. dysenteriae is a smooth organism with specific immunochemical, biochemical and pharmacological properties. From several wild types isolated from 
cases of Shiga dysentery, we have selected strain $136 \mathrm{~T}$ as a typical Shiga bacillus (and maintained it as lyophilized 'copies' all 'fresh from nature'). The series of stepwise mutations presented here, from 136-T $\mathrm{Lac}^{-}$to $136-0 \mathrm{Lac}^{-}$to $136-\mathrm{R} 1 \mathrm{Lac}^{-}$ to $136-\mathrm{R} 4 \mathrm{Lac}^{-}$are probably the same steps by which strains Sh 15 , Sh 60 and other rough strains, considered in this paper, came into being. While the wild type is resistant to several of the coliphages, various colony-form mutants, which exhibit different surface antigens, are sensitive to a wide range of coliphages. Mutant rough strains, several steps removed from the wild type, are sensitive to all of the standard coliphages. It is from this latter group of extreme-rough organisms that one isolates $\mathrm{Lac}^{+} \boldsymbol{S}$. dysenteriae. Considered as a mutant of the wild type, a $\mathrm{Lac}^{+}$mutant represents then a very rare event.

Our evidence seems to indicate that Shigella dysenteriae is cryptic with respect to $\beta$-galactosidase (and to the enzymes involved in maltose and mannitol utilization). This 'walled off' state is attributable to surface properties peculiar to Shiga's bacillus and has, probably, only an apparent relation to $\beta$-galactoside system. The lactose utilization system in Escherichia coli involves three effects which, genetically, are closely linked : $\beta$-galactoside permease $(\mathrm{Y}), \beta$-galactosidase $(\mathrm{Z})$ and the inducible condition (i) (see Pardee et al. 1959). While the $\beta$-galactosidase of $S$.dysenteriae is immunochemically identical with that of $E$. coli, there is as yet no evidence that the two organisms harbour identical transport (permease) systems. If they do, then other surface structures in the case of Shiga's bacillus serve to block the permease (Y) thus rendering the organism phenotypically $\mathrm{Y}^{-}$. Such a masking of phenotype would be analogous to the state of the mucoid mutant of a phage-sensitive bacterium which is itself resistant to phage, not because it lacks phage receptors but because its phage receptors are covered by a surface layer of polysaccharide.

It is not surprising that Shigella dysenteriae has an enzyme in common with Escherichia coli, for interfertile populations usually have much in common. As a matter of fact the number of cross-reacting antigens shared by $S$. dysenteriae and $E$. coli B, for example, appears to be considerable, for when lysates of these organisms are placed on areas of agar equidistant from Shiga antitoxin, several common antigen-antibody lines are formed. These lysates (complexes of phage and bacterium) offer a simple and effective means of releasing for immunochemical identification various biologically-active macromolecules not ordinarily detected in microorganisms or as their extracellular products. It is possible by removing borings of agar (with a capillary pipette) at various distances from the phage + bacterium complex on TMG plates, to obtain samples having different concentrations of $\beta$-galactosidase. By this means $\beta$-galactosidase activity can be detected in strains producing only slight amounts of active enzyme. In examining carrier clones of the $\mathrm{Z}^{-}$coli strains furnished by Dr J. Monod we observed one strain which produced an impressive $\beta$-galactosidase anti- $\beta$-galactosidase line in TMG MacConkey agar but which showed only an extremely small amount of $\beta$-galactosidase activity. Presumably, most of the $\beta$-galactosidase produced by this strain was inactive (see Perrin et al. 1959). We mention this here because it has some bearing on the quality and amounts of $\beta$-galactosidase to be expected in other micro-organisms.

Shigella dysenteriae strain Sh15. By conventional methods of examination the Sh 15 strain of Shigella dysenteriae would appear to be $\mathrm{Z}^{-}$. We were unable to obtain $\mathrm{Lac}^{+}$mutants of it under the conditions here described for selecting $\mathrm{Lac}^{+}$mutants 
of 136-R 4. It is possible, however, to prepare $\mathrm{Lac}^{+}$complexes between strain Sh 15 and phage $T 7^{\text {sh }}$. The fusion of faint but definite antigen-antibody lines, formed between these complexes ( $\left.\mathrm{T} 7^{\mathrm{sh}}, 136-\mathrm{R} 4\right)$ and anti- $\beta$-galactosidase (rabbit serum), with bona fide $\beta$-galactosidase anti- $\beta$-galactosidase lines has been observed. This indicates that the Z-region is present in strain Sh 15. Dr S. Luria (personal communication) has additional evidence which suggests that strain $\mathrm{Sh} 15$ is $\mathrm{Z}^{+}$. We pointed out (Table 5) that strain Sh 15 produced minute amounts of active enzyme. In addition, its output of material immunochemically reactive with anti- $\beta$-galactosidase was low. It would seem, therefore, that though strain $\mathrm{Sh} 15$ is $\mathrm{Z}^{+}$, the Z-region of its genome is much impaired.

We are indebted to Drs E. S. Lennox and M. J. Osborn for reading the manuscript and for their general interest in the subject with which this paper is concerned. This work was carried out under a grant from the Allergy and Infectious Diseases section of the National Institutes of Health, the U.S. Public Health Service.

\section{REFERENCES}

Adams, J. N. \& Luria, S. E. (1958). Transduction by bacteriophage pl: abnormal phage function of transducing particles. Proc. nat. Acad. Sci., Wash. 44, 590.

Adams, M. H. (1959). Bacteriophages. New York: Academic Press.

Adams, M. H. \& Park, B. H. (1956). An enzyme produced by a phage-host cell system. II. The properties of the polysaccharide depolymerase. Virology, 2, 719.

BARKSDALE, L. (1959). Lysogenic conversions in bacteria. Bact. Rev. 23, 202.

Barksdale, W. L. \& Pappenheimer, A. M. (1954). Phage-host relationships in nontoxigenic and toxigenic diphtheria bacilli. J. Bact. 67, 220.

Cohn, M., Lennox, E. S. \& Spiegelman, S. (1960). On the behaviour of the $\mathbf{P}_{\mathbf{z}}-{ }^{\prime} \beta$-galactoside system' introduced into Shigella dysenteriae. Biochem. biophys. Acta, 39, 255.

Demerec, M. \& Fano, V. (1945). Bacteriophage resistant mutants in Escherichia coli. Genetics, 30, 119.

Fraser, D. K. (1957). Host range mutants and semitemperate mutants of bacteriophage T3. Virology, 3, 527.

Lederberg, J. (1956). Bacterial protoplasts induced by penicillin. Proc. nat. Acad. Sci., Wash. 42, 574.

Lisbonne, M. \& Carrène, L. (1923). Obtention du principe Iytique pour le Bacille de Shiga par culture filtrée de B. coli. C.R. soc. biol., Paris, 88, 724.

Luria, S. E. \& Burrous, J. W. (1957 a). Hybridization between Shigella and Escherichia and the production of new Shigella serotypes. Bact. Proc. p. 51.

LURIA, S. E. \& Burrous, J. W. (1957b). Hybridization between Escherichia coli and Shigella. J. Bact. 74, 461.

LwoFf, A. (1953). Lysogeny. Bact. Rev. 17, 269.

Mueller, J. H. \& Miller, P. A. (1941). Production of diphtheric toxin of high potency $(100 \mathrm{Lf})$ on a reproducible medium. J. Immunol. 40, 21.

Pardee, A. B., JACob, F. \& Monod, J. (1959). The genetic control and cytoplasmic expression of 'Inducibility' in the synthesis of $\beta$-galactoside of $E$. coli. J. molec. Biol. 1, 165.

Perrin, D., Bussard, A. \& Monod, J. (1959). Sur la présence de protéines apparantées à la galactoside chez certains mutants d'Escherichia coli. C.R. Acad. Sci. $249,778$.

SpIzizen, J. (1957). Infection of protoplasts by disrupted T2 virus. Proc. nat. Acad. Sci., Wash. 43, 694.

van Heyningen, W. E. (1955). The neurotoxin of Shigella shigae 5. The effect of iron and related metals on the growth, respiration and toxin production of Shigella shigae and related organisms. Brit. J. exp. Path. 36, 373.

Zinder, N. D. (1957). Lysogenic conversions in Salmonella typhimurium. Science, 126, 1237. 


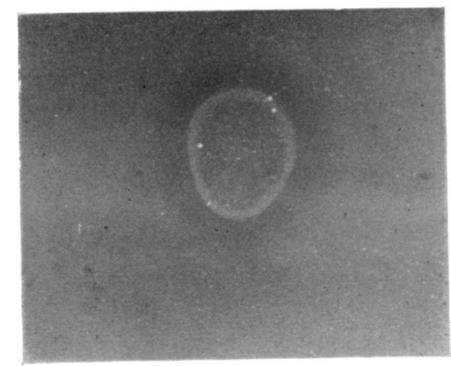

Fig. 1

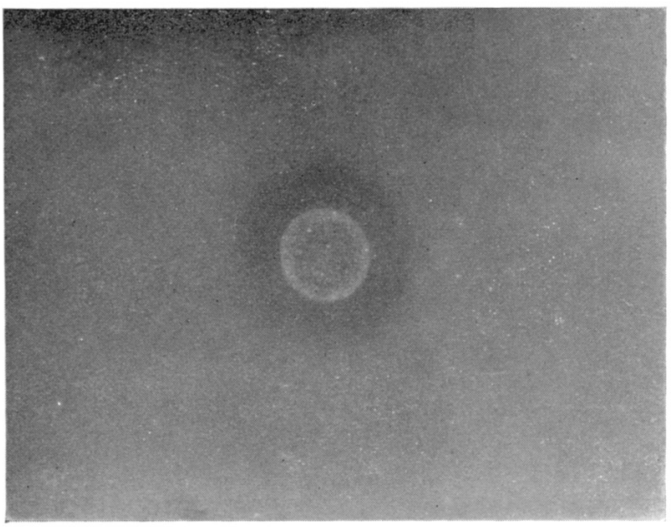

Fig. 2

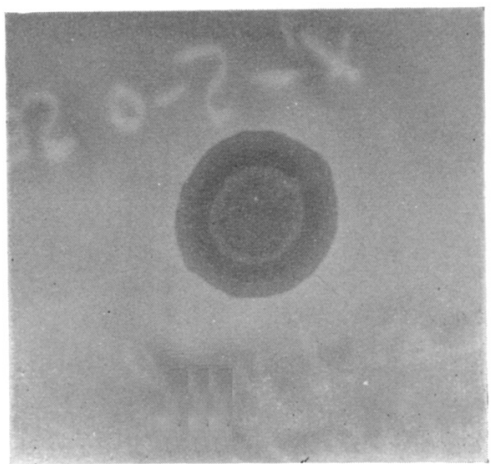

Fig. 3

ROHBONG LI, L. BSMRKSDALE AND L. GMRMISL: 


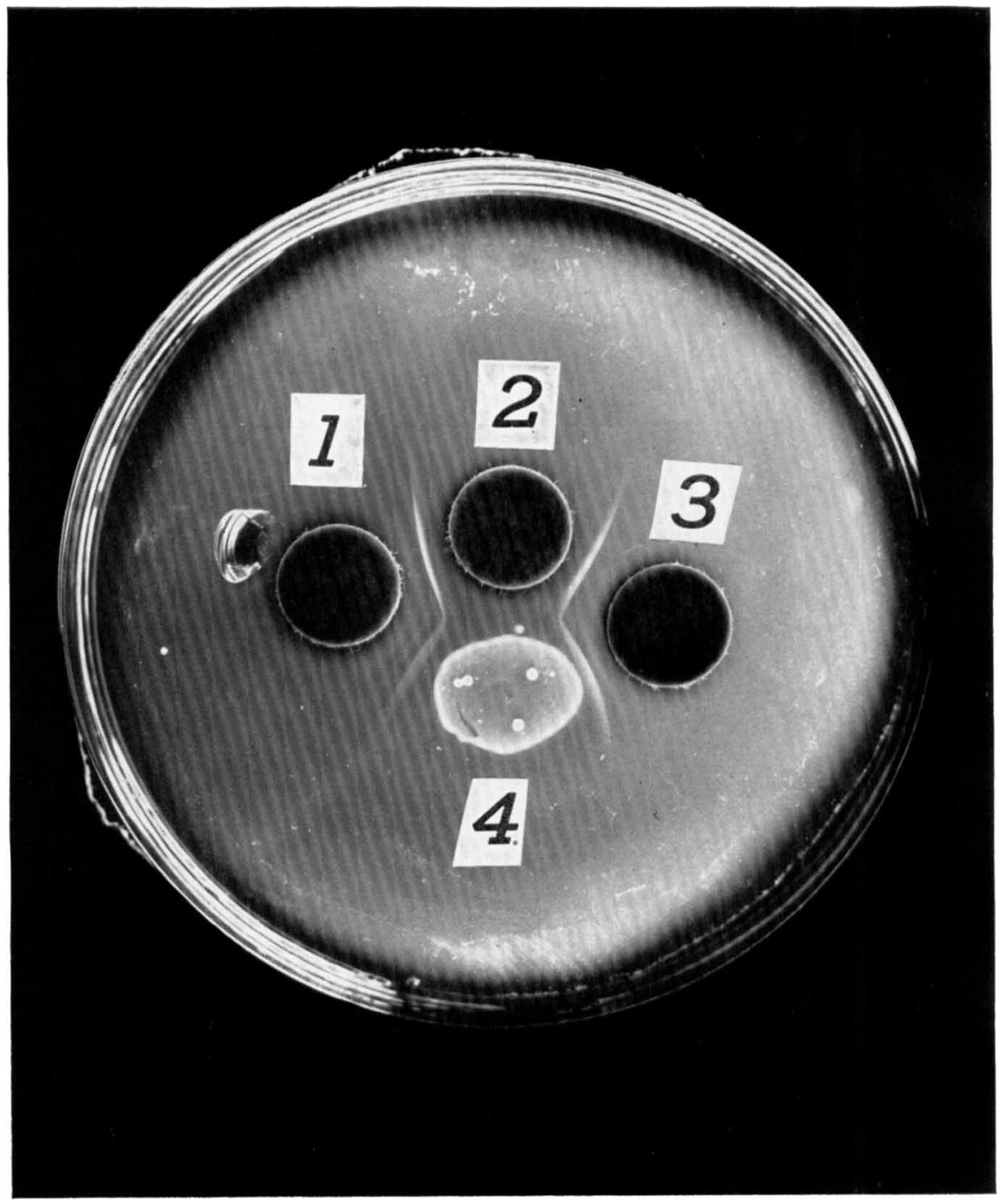

Fig. 4

LOIBONG LI, L. BARLESILAL AND I. GARMISE 
EXPLANATION OF PLATES

Plate 1

Figs. 1 and 2 are photographs of holes produced in a lawn (prepared from an acetone powder of Shigella dysenteriae 136-R4) by a carrier clone (lysate) of 136-R4.T $7^{\mathrm{sh}}$.

Fig. 3. A photograph of the lysis of living 186-R4 caused by the diffusion of phage and endolysin from carrier clone (lysate) of $136-\mathrm{R} 4 . \mathrm{T}^{\mathrm{7b}}$. Note the differentiation of the lysed area into clear inner portion and outer halo.

Plate 2

Fig. 4. The fusion of antigen-antibody lines formed between the $\beta$-galactosidase released by carrier clone 136-R4 $\left(\mathrm{Lac}^{-}\right) . \mathrm{Tz}^{\mathrm{sh}}$ (position 4) with antigen-antibody lines formed between purified $\beta$-galactosidase (position 2) and rabbit antiserum directed against $\beta$-galactosidase (positions 1 and 3). 